\title{
BMJ Open Risky driving among UK regular armed forces personnel: changes over time
}

\author{
Rebecca J Syed Sheriff, ${ }^{1,2}$ Harriet J Forbes, ${ }^{1}$ Simon C Wessely, ${ }^{1}$ Neil Greenberg, ${ }^{3}$ \\ Norman Jones, ${ }^{3}$ Mohammed Fertout, ${ }^{3}$ Kate Harrison, ${ }^{4}$ Nicola T Fear ${ }^{3}$
}

To cite: Sheriff RJS,

Forbes HJ, Wessely SC, et al. Risky driving among UK regular armed forces personnel: changes over time. BMJ Open 2015;5 e008434. doi:10.1136/ bmjopen-2015-008434

- Prepublication history and additional material is available. To view please visit the journal (http://dx.doi.org/ 10.1136/bmjopen-2015008434)

These authors contributed equally.

Received 7 April 2015

Revised 11 August 2015

Accepted 27 August 2015

\section{(D) CrossMark}

${ }^{1}$ King's Centre for Military Health Research, King's College London, Weston Education Centre, London, UK

${ }^{2}$ Centre for Mental Health Research, ANU College of Medicine, Biology and Environment, Australia National University, Australian Capital Territory, Australia ${ }^{3}$ Academic Centre for Defence Mental Health, King's College London, Weston Education Centre, London, UK ${ }^{4}$ MOD, Defence Statistics Health, Bristol, UK

Correspondence to Professor Nicola T Fear; nicola.t.fear@kcl.ac.uk

\section{ABSTRACT}

Objectives: To compare the prevalence of selfreported risky driving in a sample of UK military personnel at 2 different time points (2004 and 2009), and to identify the incidence of new onset risky driving and possible determinants of becoming a new risky driver.

Methods: Data were used from 2 phases of a military cohort study investigating the health and well-being of UK military personnel between 2004 and 2009. Participants were included if they were undertaking regular (rather than reserve) engagements, had completed both surveys and reported being a driver at both surveys. Univariable and multivariable logistic regression analyses were performed to examine the relationship between risky driving status and sociodemographic and military characteristics. Data analysis was conducted in 2011.

Results: The prevalence of risky driving reduced from $18 \%$ to $14 \%$, over an average of 3.3 years. The incidence of new onset risky driving was $7 \%$. Predictors for becoming a new risky driver were: younger age, not being in a relationship at phase 2 and harmful alcohol use. Those deployed after 2007 were less likely to become risky drivers following deployment, compared with those deployed before 2007 (adjusted OR 0.62 (95\% Cl 0.40 to 0.95)).

Conclusions: The prevalence of becoming a risky driver appears to have reduced over time. This paper suggests a number of explanations for this reduction, including changes in the way that the UK military have dealt with road safety with the introduction of the road safety campaign (in 2007).

\section{INTRODUCTION}

Road traffic accidents (RTAs) are the leading causes of death in young people in the USA and UK. ${ }^{1}{ }^{2}$ Deaths from RTAs are also a particular problem in the UK military. In 2006, the number of deaths due to land transport accidents (unrelated to hostile action) in the UK regular Armed Forces was $435 \%$ higher than in the general population (standardised mortality ratio (SMR): $535,95 \%$ CI 416 to 687). ${ }^{3}$ In 2006, the single largest cause of death was land transport accidents, accounting for 59 deaths (31\% of all deaths) in the UK regular Armed Forces. ${ }^{4}$ We know from a

\section{Strengths and limitations of this study}

A road safety campaign was introduced for military personnel returning from deployment; this is the first study to assess whether there is any evidence the campaign was effective.

- The results presented here used data from two phases of a military cohort study investigating the health and well-being of UK military personnel between 2004 and 2009 and allow us to assess changes in driving behaviours over time.

- Not all participants responded to both surveys; however, the analyses have taken account of response weights.

- Capturing risky behaviours through self-report can be prone to bias, thus participants may have under-reported risky driving.

previous study that the self-reported prevalence of risky driving in the UK military is $19 \% .^{5}$

Risk factors for RTAs in military and general populations include being male, young, unmarried and of lower educational attainment, ${ }^{6-9}$ and within military populations, combat experience appears to confer a higher risk, ${ }^{10-13}$ although this diminishes with time after deployment. ${ }^{14-16}$ A recent study of American veterans from the Iraq and Afghanistan conflicts suggested they performed more poorly on a driving-simulator assessment, compared with a civilian control group, raising further concerns about driving safety after leaving military service. ${ }^{17}$

There is some evidence that road safety campaigns reduce the number of RTAs. A meta-analysis of 67 studies of road safety campaigns from 12 countries between 1975 and 2007 showed overall a $9 \%$ reduction in RTAs. ${ }^{18}$ The UK Armed Forces developed a campaign to reduce risky driving in military personnel immediately following deployment in a satirical video called the 'Grim Reaper'. ${ }^{19}$ This has been shown to UK military personnel returning from deployment since September 2007.

The objective of this study was to compare the prevalence of self-reported risky driving 
in the same sample of UK military personnel at two different time points using data from the King's Centre for Military Health Research's (KCMHR) Military Cohort Study. ${ }^{20}{ }^{21}$ In addition, to identify the incidence of new onset risky driving and the determinants of becoming a new risky driver, particularly whether the road safety campaign introduced in the military in 2007 had an impact on self-reported risky driving.

\section{METHODS}

\section{Data source}

Data were used from phases 1 and 2 of the KCMHR Military Cohort Study. ${ }^{20}{ }^{21}$ These were the first and second phases of an ongoing cohort study of UK military personnel assessing physical and mental health consequences of deployment to Iraq and Afghanistan. Phase 1 data were collected between June 2004 and March 2006 and phase 2 between November 2007 and September 2009. There were 10305 participants at phase 1 (response rate was 58.9\%). In total, 6429 participants completed phase 2 (follow-up response rate $68.4 \%)$. Response at phase 2 was associated with older age, being female, being an officer and being of regular engagement type. There was no evidence that response was associated with mental health status. ${ }^{20}$

\section{Variables}

Data on a wide range of sociodemographic, military and health factors were collected via self-completed questionnaires at both phases. For the purposes of these analyses, the following variables were considered.

\section{Risky driving}

Risky driving has been defined as anyone who sometimes, seldom, or never wears a seatbelt; or who drives more than 10 miles/h (mph) above the limit (10 $\mathrm{mph}$ is equivalent to $16 \mathrm{~km} / \mathrm{h}(\mathrm{kph}))$ in a built-up area, or more than $20 \mathrm{mph}$ above the limit on a motorway (20 $\mathrm{mph}$ is equivalent to $32 \mathrm{kph}$ ). Questions on seatbelt usage and speeding were adapted from the study by Bell $e t a t^{6}$ and this definition has been used previously. ${ }^{5}$ Self-reported risky driving behaviours from both phases were used to define personnel as: non-risky at both phases, risky at phase 1 but not phase 2, risky at phase 2 but not phase 1 and risky at both phases.

\section{Static variables}

Static sociodemographic and military factors taken from phase 1 included sex, educational attainment, childhood antisocial behaviour, rank, service and role in parent unit. A measure of childhood antisocial behaviour ${ }^{22} 23$ defined as anyone who 'often used to get into physical fights at school', and either 'often used to play truant from school', or 'was suspended or expelled from school', or 'did things that should have got them (or did get them) into trouble with the police'. Sociodemographic factors from phase 2 also included age, marital status and ever having deployed to Iraq or Afghanistan. There were seven questions on potentially traumatic deployment experiences, collected at phase 2, which were summed and collapsed into three categories (no experiences, 1-3 experiences, 4+experiences) for analysis: did you 'give aid to wounded', 'see personnel seriously wounded or killed', 'come under small arm/ rocket propelled grenade (RPG) fire', 'come under mortar/artillery fire/rocket attack', 'experience a landmine strike', 'experience hostility from Iraqi/Afghani civilians' and 'handle bodies'.

\section{Dynamic variables}

The following dynamic variables were generated: age change between survey points in whole years, age group change (remained under 35 years, became over 35 years, stayed over 35 years; 35 years was taken as the cut-off as cross-tabulations indicated that risky driving showed a decline after this age), deployed since phase 1, left service, change in relationship status, change in alcohol misuse status and had a RTA. Alcohol misuse was defined as having a score of $\geq 16$ on the WHO's Alcohol Use Disorders Identification Test (AUDIT) which signifies the harmful use of alcohol. ${ }^{24}$ Among personnel deployed between phases 1 and 2, two further dynamic variables were generated; years since last deployment was the time since last deployment to phase 2 questionnaire completion, and deployment after the release of the Grim Reaper video was classified as anyone deploying after September 2007.

\section{Study sample}

The sample comprised of personnel who had completed both phases 1 and 2 of the KCMHR cohort study. Only regular personnel were included. Reservists were excluded because they often have military roles, social backgrounds and postdeployment experiences that differ to regulars. ${ }^{21} 25$ Finally, only those who were drivers at both phases were included (see online supplementary figure A1).

\section{Statistical analysis}

Overall prevalence of risky driving at both phases, by age and service, was calculated. The distribution of phase 1 baseline and phase 2 sociodemographic and military characteristics by risky driving status were tabulated to examine the relationship between them. Univariable and multivariable logistic regression analyses were performed to examine the relationship between new onset risky driving and the dynamic variables. Subgroup analyses were carried out among personnel deploying between phases 1 and 2, to examine the effect of deploying before or after the Grim Reaper video on risky driving status. ORs, 95\% CIs and two-sided $\mathrm{p}$ values are presented. Response weights were generated to account for nonresponse. Response weights were defined as the inverse probability of responding once sampled and were generated using factors shown empirically to predict response 
Table 1 Distribution of risky driving at each phase by age, sex and service

\begin{tabular}{|c|c|c|}
\hline & $\begin{array}{l}\text { Phase } 1 \\
\text { N, \% (95\% Cl) }\end{array}$ & $\begin{array}{l}\text { Phase } 2 \\
\text { N, \% (95\% Cl) }\end{array}$ \\
\hline All & $834 / 4987(17.8(16.7$ to 18.8$))$ & $639 / 5009(13.6(12.5$ to 14.5$))$ \\
\hline \multicolumn{3}{|l|}{ By sex } \\
\hline Male & $786 / 4515(18.4(17.2$ to 19.6$))$ & $597 / 4534(14.0$ (12.9 to 15.0$))$ \\
\hline Female & $48 / 472(10.5$ (7.7 to 13.3$))$ & $42 / 475(9.0(6.4$ to 11.6$))$ \\
\hline \multicolumn{3}{|l|}{ By service } \\
\hline Navy & $30 / 152(20.2(13.7$ to 26.7$))$ & $25 / 152(16.7$ (10.7 to 22.7$))$ \\
\hline Royal Marines & $84 / 701$ (12.6 (10.1 to 15.2$))$ & $59 / 705(9.2(6.9$ to 11.4$))$ \\
\hline Army & $644 / 3011(22.6(21.1$ to 24.2$))$ & $479 / 3026(16.7(15.3$ to 18.1$))$ \\
\hline Royal Air Force & $76 / 1123(6.7(5.5$ to 8.5$))$ & $76 / 1126(7.0(5.5$ to 8.5$))$ \\
\hline
\end{tabular}

(sex, rank, age). The weighted analyses provide valid results under the assumption that the data are missing at random and that the observed variables modelled to drive non-response were correctly identified. ${ }^{20}$ All analyses were performed using STATAV.11.0.

\section{RESULTS}

Of 8154 drivers at phase $1,{ }^{\mathrm{i}} 5020(61.6 \%)$ responded to phase 2 and were still drivers, and formed the sample for these analyses (see online supplementary figure A1). Those lost to follow-up at phase 2 were more likely to be risky drivers at phase $1(664 / 3081,21.6 \%)$ compared with those followed up $\left(845 / 5073,16.7 \%\right.$; based on a $\chi^{2}$ test, $\mathrm{p}<0.001)$.

\section{Prevalence of risky driving}

Among the sample, $17.8 \%$ were risky drivers at phase 1 , and $13.6 \%$ were risky drivers at phase 2 (table 1 ). The overall prevalence of risky driving was greater among male Army and Navy personnel, at both phases (table 1).

\section{Changes in risky driving status}

There was a strong association between risky driving status at phases 1 and $2(\mathrm{p}<0.001)$. The incidence of new onset risky driving was $7 \%$ (276/4143) (table 2). The average time elapsed between phases 1 and 2 was 3.29 years (SD 0.62). Generally, the non-risky drivers at both phases $(n=3867,76.4 \%)$ were older, reported less childhood antisocial behaviour, more educational qualifications, were more commonly in the Navy or RAF, more likely to be married at phase 2 , were more likely to be officers, more likely to be in a non-combat role and less likely to have ever been deployed than those drivers who were risky at any or both phases (table 3).

Personnel under 35 years of age at phase 1 were more likely to become risky drivers (whether they aged into the above 35 category or not), compared with phase 1

${ }^{\mathrm{i}}$ Paper on risky driving at phase 1 analysed a total of 8127 participants However, 29 late responders (who were regulars and drive) have since been added to the data set, and two participants were removed due to errors. personnel who were over 35 years old (table 4). Personnel who were not in a relationship at phase 2, and personnel who had ever misused alcohol, were more likely to become risky drivers by phase 2 . There was some evidence that being deployed to Iraq or Afghanistan was associated with an increased chance of becoming a risky driver; however, the effect was removed after adjusting for the dynamic variables. Among non-risky drivers at phase 1 who had deployed between the phases, personnel who had deployed after the release of the Grim Reaper video were less likely to become risky drivers (table 5).

The overall number of traumatic deployment experiences was lower after the introduction of the Grim Reaper video campaign in 2007 (of the 1760 participants deploying between phases 1 and 2, 822/941 participants (87\%) reported at least one traumatic event before the campaign, compared with $627 / 762(82 \%)$ after its release). However, after adding traumatic deployment experiences to the second model in table 5, deploying after the introduction of Grim Reaper video campaign was still associated with a reduced risk of becoming a risky driver (OR $0.62,95 \%$ CI 0.40 to 0.96 ; data not shown).

\section{DISCUSSION}

\section{Main findings}

Among a cohort of UK military personnel, the prevalence of risky driving reduced from $17.8 \%$ to $13.6 \%$, over an average time period of 3.29 years. The incidence of new onset risky driving was $7 \%$. Risk factors for

Table 2 Risky driving status among a cohort of 4976 regular personnel with risky driving status available at phases 1 and 2

\begin{tabular}{lllr}
\hline \multicolumn{4}{c}{ Risky driving status at phase 1 } \\
\cline { 2 - 3 } & Risky, n (\%) & Non-risky, $\mathbf{n ~ ( \% ) ~}$ & $\mathbf{n}$ \\
\hline Risky driving status at phase 2 & & \\
Risky & $359(43.7)$ & $276(7.0)$ & 635 \\
Non-risky & $474(56.3)$ & $3867(93.0)$ & 4341 \\
N & $833(100)$ & $4143(100)$ & 4976 \\
\hline \multicolumn{4}{l}{ Analyses are adjusted for non-response weights. }
\end{tabular}


Table 3 Sociodemographic and military characteristics of the follow-up sample, at $\mathrm{P} 2$, by risky driving status $\left(\mathrm{N}=5020^{*}\right)$

\begin{tabular}{|c|c|c|c|c|c|}
\hline Variable & $\begin{array}{l}\text { All } \\
\text { n (\%) }\end{array}$ & $\begin{array}{l}\text { Risky driver } \\
\text { at P1 and P2 } \\
\text { n (\%) }\end{array}$ & $\begin{array}{l}\text { Risky driver } \\
\text { at P1 only } \\
\text { n (\%) }\end{array}$ & $\begin{array}{l}\text { Risky driver } \\
\text { at P2 only } \\
\text { n (\%) }\end{array}$ & $\begin{array}{l}\text { Non-risky } \\
\text { at P1 and P2 } \\
n(\%)\end{array}$ \\
\hline All & $5020(100)$ & $359(7.8)$ & $474(10.0)$ & $276(5.8)$ & 3867 (76.4) \\
\hline \multicolumn{6}{|l|}{ Sociodemographic factors } \\
\hline \multicolumn{6}{|l|}{ Age (years) } \\
\hline$<25$ & $100(2.7)$ & $15(5.3)$ & $13(3.5)$ & $10(4.7)$ & $60(2.1)$ \\
\hline $25-29$ & $795(19.1)$ & $103(32.9)$ & $109(26.7)$ & $58(24.7)$ & $517(16.3)$ \\
\hline $30-34$ & 964 (19.7) & $86(23.4)$ & $130(27.6)$ & $72(25.9)$ & $669(17.8)$ \\
\hline $35-39$ & $1243(23.9)$ & $84(21.4)$ & $118(23.0)$ & $73(24.9)$ & $959(24.2)$ \\
\hline $40+$ & $1918(34.7)$ & $71(17.0)$ & $104(19.2)$ & $63(19.8)$ & 1662 (39.6) \\
\hline \multicolumn{6}{|l|}{ Gender } \\
\hline Male & 4545 (91.3) & $343(96.1)$ & 442 (93.9) & $251(92.0)$ & $3468(90.4)$ \\
\hline Female & $475(8.7)$ & $16(3.9)$ & $32(6.1)$ & $25(8.1)$ & $399(9.6)$ \\
\hline \multicolumn{6}{|l|}{ Marital status } \\
\hline Married/cohabiting & $4181(83.0)$ & $279(77.7)$ & 384 (80.9) & $203(72.7)$ & 3277 (84.5) \\
\hline Single & $437(9.4)$ & $46(13.1)$ & 49 (10.8) & 33 (13.1) & $304(8.5)$ \\
\hline Separated/widowed/divorced & $386(7.7)$ & $33(9.2)$ & $40(8.3)$ & 39 (14.3) & $273(7.1)$ \\
\hline \multicolumn{6}{|l|}{ Childhood antisocial behaviour } \\
\hline No & $4184(83.1)$ & $226(62.6)$ & $351(73.6)$ & $210(77.1)$ & 3357 (86.8) \\
\hline Yes & 799 (16.9) & $130(37.4)$ & $120(26.4)$ & $61(22.9)$ & 485 (13.2) \\
\hline \multicolumn{6}{|l|}{ Educational qualifications } \\
\hline None & $313(6.7)$ & $32(9.5)$ & $39(8.5)$ & $28(11.2)$ & $211(5.8)$ \\
\hline Ordinary levels or equivalent & $1725(38.0)$ & $132(40.0)$ & $192(44.1)$ & $107(42.7)$ & $1273(36.5)$ \\
\hline Advanced levels or equivalent & $1676(35.8)$ & $132(38.3)$ & $158(34.5)$ & $86(33.8)$ & $1291(36.0)$ \\
\hline University degree or equivalent & $1054(19.6)$ & $50(12.3)$ & 69 (12.9) & 38 (12.4) & 889 (21.7) \\
\hline \multicolumn{6}{|l|}{ In service at $\mathrm{P} 2$} \\
\hline Yes & $3570(71.0)$ & $262(72.3)$ & $357(75.0)$ & $198(71.2)$ & $2721(70.3)$ \\
\hline No & $1445(29.0)$ & 97 (27.7) & $117(25.0)$ & 78 (28.8) & $1141(29.7)$ \\
\hline \multicolumn{6}{|l|}{ Military factors } \\
\hline \multicolumn{6}{|l|}{ Rank } \\
\hline Other (including NCO’s) & 3726 (78.2) & $302(87.2)$ & $380(83.5)$ & $226(85.2)$ & $2781(76.0)$ \\
\hline Officer & $1294(21.8)$ & $57(12.8)$ & $94(16.5)$ & $50(14.8)$ & $1086(24.1)$ \\
\hline \multicolumn{6}{|l|}{ Service } \\
\hline Naval & 705 (13.6) & $30(8.1)$ & $54(10.9)$ & 27 (10.0) & $590(14.8)$ \\
\hline Royal Marines & $153(3.2)$ & $11(3.0)$ & $19(4.0)$ & $14(5.1)$ & $107(2.9)$ \\
\hline Army & $3034(61.4)$ & $286(80.6)$ & $357(76.1)$ & $191(69.4)$ & $2169(56.8)$ \\
\hline Royal Air Force & $1128(21.9)$ & $32(8.3)$ & $44(8.9)$ & $44(15.5)$ & $1001(25.6)$ \\
\hline \multicolumn{6}{|l|}{ Role in parent unit } \\
\hline Non-combat & 4078 (81.2) & $253(70.6)$ & $342(72.0)$ & $197(72.6)$ & $3252(84.1)$ \\
\hline Combat & $900(18.8)$ & $101(29.4)$ & $129(28.0)$ & $74(27.5)$ & $587(15.9)$ \\
\hline \multicolumn{6}{|l|}{ Ever deployed } \\
\hline No & 3260 (64.2) & 202 (55.9) & $271(57.2)$ & $158(56.5)$ & $2606(66.7)$ \\
\hline Yes & $1760(35.8)$ & $157(44.1)$ & $203(42.8)$ & $118(43.5)$ & $1261(33.4)$ \\
\hline
\end{tabular}

becoming a risky driver included: younger age, not being in a relationship at phase 2 , and alcohol misuse at either or both phases. Those deployed after 2007, when the road safety campaign was introduced, were less likely to become risky drivers following deployment, compared with those deployed before 2007.

\section{Reduction in risky driving}

The reduction in the prevalence of risky driving among our sample may reflect the effect of increasing age, the introduction of a road safety campaign, a possible change in the nature of deployments and/or possible changes in driving practices on deployment.

Owing to the nature of our study design, participants aged by an average of 3.3 years between the two phases. We would expect increasing age alone to reduce risky driving behaviours. Studies show that in military populations younger drivers are more likely to report risky behaviours. ${ }^{5}$ However, we suggest that age alone is unlikely to fully account for the reduction in risky driving. 
Table 4 Variables associated with becoming a risky driver at P2, compared with not becoming a risky driver at P2, among all non-risky drivers at $\mathrm{P} 1(\mathrm{~N}=4143)$

\begin{tabular}{|c|c|c|c|c|}
\hline Variable & $\begin{array}{l}\text { Becomes risky } \\
\text { n (\%) }\end{array}$ & OR $(95 \% \mathrm{Cl})$ & $\begin{array}{l}\text { AOR }(95 \% \mathrm{Cl}) \\
\text { Model } 1\end{array}$ & $\begin{array}{l}\text { AOR }(95 \% \mathrm{Cl}) \\
\text { Model } 2\end{array}$ \\
\hline Total & \multicolumn{4}{|l|}{$276 / 4143$} \\
\hline \multicolumn{5}{|l|}{ Sociodemographic factors } \\
\hline $\begin{array}{l}\text { Age change between } P 1 \text { and } P 2 \text { in years } \\
\text { (mean, SD) }\end{array}$ & $3.33(0.65)^{*}$ & $1.18(0.98$ to 1.43$)$ & $1.10(0.91$ to 1.34$)$ & - \\
\hline \multicolumn{5}{|l|}{ Age group change } \\
\hline Remained under 35 years & 140/1385 (10.4) & 2.68 (2.02 to 3.54$)$ & 2.28 (1.14 to 2.43$)$ & 1.88 (1.37 to 2.59$)$ \\
\hline Became over 35 years & $51 / 694(7.6)$ & 1.89 (1.32 to 2.70$)$ & $1.66(1.14$ to 2.43$)$ & 1.57 (1.06 to 2.30$)$ \\
\hline Stayed over 35 years & $85 / 2063$ (4.2) & 1.00 & 1.00 & 1.00 \\
\hline \multicolumn{5}{|l|}{ Marital status change } \\
\hline In a relationship at $\mathrm{P} 1$ and $\mathrm{P} 2$ & $178 / 3111(6.0)$ & 1.00 & 1.00 & 1.00 \\
\hline Not in a relationship at $\mathrm{P} 1$ and $\mathrm{P} 2$ & $39 / 372(11.2)$ & 1.97 (1.36 to 2.85$)$ & 1.98 (1.35 to 2.92$)$ & $1.53(1.02$ to 2.30$)$ \\
\hline In a relationship at $\mathrm{P} 1$ and not at $\mathrm{P} 2$ & $33 / 275$ (12.7) & 2.27 (1.52 to 3.38$)$ & 2.21 (1.46 to 3.36$)$ & 1.67 (1.10 to 2.53$)$ \\
\hline $\begin{array}{l}\text { Not in a relationship at } \mathrm{P} 1 \text { but in a } \\
\text { relationship at } \mathrm{P} 2\end{array}$ & 25/364 (7.0) & $1.18(0.76$ to 1.83$)$ & 1.08 (0.67 to 1.72$)$ & $0.87(0.54$ to 1.41$)$ \\
\hline \multicolumn{5}{|l|}{ Health factors } \\
\hline \multicolumn{5}{|l|}{ Alcohol misuse } \\
\hline Never a case & $189 / 3509(5.6)$ & 1.00 & 1.00 & 1.00 \\
\hline Remained a case & $31 / 168(19.1)$ & 3.97 (2.61 to 6.04$)$ & $3.46(2.21$ to 5.41$)$ & $2.83(1.79$ to 4.46$)$ \\
\hline Became a case & $27 / 178(16.1)$ & 3.21 (2.07 to 4.98$)$ & 3.12 (2.00 to 4.87$)$ & 2.64 (1.67 to 4.17$)$ \\
\hline No longer a case & 29/269 (11.2) & 2.11 (1.39 to 3.20$)$ & 1.88 (1.21 to 2.93$)$ & 1.60 (1.02 to 2.53$)$ \\
\hline \multicolumn{5}{|l|}{ Had a RTA between questionnaires } \\
\hline No & $261 / 3771(6.8)$ & 1.00 & 1.00 & 1.00 \\
\hline Yes & $15 / 111(14.2)$ & 2.26 (1.29 to 3.98$)$ & $1.58(0.83$ to 3.01$)$ & 1.49 (0.77 to 2.89$)$ \\
\hline \multicolumn{5}{|l|}{ Military factors } \\
\hline \multicolumn{5}{|l|}{ Left service } \\
\hline Still serving & 196/2884 (7.2) & 1.00 & 1.00 & 1.00 \\
\hline Still not serving & $25 / 414(6.6)$ & $0.91(0.59$ to 1.40$)$ & $0.87(0.51$ to 1.05$)$ & $1.06(0.65$ to 1.73$)$ \\
\hline Left service & $53 / 799(7.1)$ & $0.99(0.72$ to 1.35$)$ & $1.01(0.73$ to 1.41$)$ & $1.15(0.81$ to 1.63$)$ \\
\hline Rejoined & $0 / 25(0.0)$ & - & - & - \\
\hline \multicolumn{5}{|c|}{ Deployed to Iraq or Afghanistan between questionnaires } \\
\hline No & $158 / 2764(6.0)$ & 1.00 & 1.00 & 1.00 \\
\hline Yes & $118 / 1379(9.0)$ & $1.54(1.20$ to 1.98$)$ & $1.44(1.09$ to 1.89$)$ & $1.26(0.95$ to 1.66$)$ \\
\hline \multicolumn{5}{|c|}{$\begin{array}{l}\text { Model 1: adjusted for P1 static variables (rank, service, childhood antisocial behaviour, education). } \\
\text { Model 2: adjusted for P1 static variables and dynamic variables (rank, service, childhood antisocial behaviour, education, age group change, } \\
\text { marital status change, deployed between questionnaires, alcohol misuse). } \\
\text { Missing values ranged from } 19 \text { (alcohol misuse) to } 261 \text { (had an RTA between questionnaires). } \\
\text { Analyses are adjusted for non-response weights. } \\
\text { *Age change among those staying non-risky: } 3.27 \text { years (SD 0.92). } \\
\text { AOR, adjusted OR; P1, phase 1; P2, phase 2; RTA, road traffic accident. }\end{array}$} \\
\hline
\end{tabular}

Factors associated with change from non-risky to risky driving behaviours

Sociodemographic factors

The finding that younger people are more likely to become risky drivers is consistent with reports from previous cohort studies. ${ }^{26} 27$ In addition, the finding that a change in relationship status (from being in a relationship to not being in a relationship) increases the likelihood of becoming a risky driver adds to previous evidence. ${ }^{5}$ Previous research demonstrates lower levels of risky driving in soldiers reporting greater psychosocial support. ${ }^{28}$ Furthermore, our findings demonstrate that the probability of becoming a risky driver for those who have never been in a relationship remains high. ${ }^{29} 30$ These findings are broadly consistent with our own given that being in a relationship is likely to confer the feeling of greater psychosocial support.

\section{Other risk taking behaviours}

Consistent with other studies, ${ }^{31-36}$ our study shows that harmful alcohol use is associated with an increased risk of becoming a risky driver.

\section{Deployment}

Previous analyses showed that deployment itself and also traumatic experiences on deployment were associated with risky driving but with a moderate effect size (those with the highest rates of exposures to traumatic experiences had an adjusted OR of becoming risky drivers of 1.69 (CI 1.31 to 2.18$)) .{ }^{5}$ The current study shows that 
Table 5 Variables associated with becoming a risky driver at phase 2, among all non-risky drivers at phase 1 who deployed between questionnaires $(\mathrm{N}=1379)$

\begin{tabular}{|c|c|c|c|c|}
\hline Variable & Becomes risky n (\%) & OR $(95 \% \mathrm{Cl})$ & $\begin{array}{l}\text { AOR }(95 \% \mathrm{Cl}) \\
\text { Model } 1\end{array}$ & $\begin{array}{l}\text { AOR }(95 \% \mathrm{Cl}) \\
\text { Model } 2\end{array}$ \\
\hline Years since & 1.83( & 1.06 (0.85 to 1.32$)$ & 1.05 (0.83 to 1.32$)$ & $1.06(0.83$ to 1.35$)$ \\
\hline \multicolumn{5}{|c|}{ Deployment in relation to Grim Reaper video September 2007} \\
\hline Before & $77 / 766(10.7)$ & 1.00 & 1.00 & 1.00 \\
\hline After & $41 / 613(6.9)$ & $0.62(0.42$ to & $0.64(0.42$ to 0.98$)$ & $0.62(0.40$ to 0.95$)$ \\
\hline \multicolumn{5}{|c|}{ Number of traumatic deployment experiences at phase 2} \\
\hline No & $12 / 218(5.6)$ & 1.00 & 1.00 & 1.00 \\
\hline & $68 / 7$ & $1.74(0$ & $1.74(0$ & $1.72(0$ \\
\hline 4+experiences & $35 / 348(10.6)$ & 2.01 (1.01 to 4.0$)$ & $1.64(0.77$ to 3.49$)$ & $1.48(0.69$ to 3.14$)$ \\
\hline
\end{tabular}

Model 1: adjusted for phase 1 static variables (rank, service, childhood antisocial behaviour, education).

Model 2: adjusted for phase 1 static variables and dynamic variables (rank, service, childhood antisocial behaviour, education, age group change, marital status change, alcohol misuse).

Forty-nine participants missing value for number of traumatic deployment experiences.

Analyses are adjusted for non-response weights.

*Years since last deployment among non-risky: 1.79 years (SD 0.88).

AOR, adjusted OR.

deployment after 2007 is associated with marginally less reported deployment-related traumatic experiences. Those deployed after 2007 were less likely to become risky drivers following deployment, compared with those deployed before 2007. This effect remains even after adjusting for age group change and the small reduction in traumatic events, and we therefore conclude that other factors must account for some of this reduction in risky driving rates.

We have identified two possible reasons for the reduction in the odds of becoming a risky driver in those deployed after 2007. First, our results may reflect the impact of the road safety campaign introduced in 2007 which attempted to encourage personnel to adopt safe driving behaviours following deployment. This road safety campaign is part of the third location decompression process, ${ }^{37}$ but the road safety presentation is the only part to address risky driving. Second, the reduction in reported risky driving following deployment may reflect increased safety of driving while on deployment.

Deployment has been identified as a risk factor for risky driving. ${ }^{5} 28$ In addition, a US study demonstrated that multiple deployments and experiencing combat on deployment were both strong predictors of motor vehicle crashes after deployment. ${ }^{38}$ Since 2006, all UK Armed Forces personnel from formed units returning from deployment overseas have taken a brief period of rest in a safe environment away from theatre and away from home. ${ }^{37}$ Since 2007, this has involved a road safety educational campaign focusing specifically on the postdeployment period including the Grim Reaper video presentation. This strategy targets a high-risk group.

The effectiveness of the road safety campaign is theoretically supported by a meta-analysis of the effect of road safety campaigns on accidents. ${ }^{18}$ Unfortunately, it is difficult to directly compare our study with others as to our knowledge no other study has investigated the protective effect of a focused campaign on individuals who have been exposed to a specific experience that increases driving risk (in this case deployment).

There are some indications that in-theatre driving practices have become more safety focused between phases 1 and 2. Such a change may have affected driving practices following deployment. While risky driving practices such as driving fast, reduced seatbelt use and rapid lane changes may be necessary for high-risk situations in-theatre on some occasions, ${ }^{39}$ the risk benefit judgement of such practices has changed over time. It is plausible that reported risky driving following deployment is a reflection of learned behaviours on deployment which continue afterwards. There is some evidence from the USA that combat driving behaviours continue after deployment and that returning military personnel can fall into these combat driving behaviours. ${ }^{40}$ Therefore, theoretically changes in in-theatre driving practices may have reduced the reporting of risky driving behaviours following recent deployments.

\section{Meaning of the study}

Encouragingly, reported risky driving behaviours in UK military personnel have reduced over time. Our findings are consistent with UK government statistics ${ }^{41}$ which show that SMRs for all fatalities among UK regular Armed Forces (regardless of when in the deployment cycle the death occurred) due to land transport accidents have reduced from 535 in 2006 to 143 in 2009, compared with the UK general population.

\section{Strengths and limitations}

This is the first study to assess changes in risky driver status in the UK military. This is also a unique opportunity to assess the utility of a road safety campaign to see if it helped to reduce the probability of becoming risky driver following deployment.

A possible source of response bias is that not all responders completed the risky driving measures. Those 
lost to follow-up at phase 2 were more likely to be risky drivers at phase $1(22 \%)$ compared with those followed up (17\%) introducing the possibility of bias. All analyses have taken account of response weights; however, residual bias may remain as only a limited number of predictors were used to generate response weights.

The use of self-reported driving data is another potential source of bias. Self-reported driving behaviours may not be an accurate reflection of actual driving behaviours, moreover the inaccuracy of the self-report may be greater for some responders than for others. Studies demonstrate that social desirability bias is associated to a greater extent with under-reporting undesirable behaviours rather than over-reporting desirable behaviours. ${ }^{42}$ This is consistent with the distortion of self-reported driving skills related to safety. ${ }^{43}$ In addition, social desirability may affect responders differently depending on various factors, such as sex (as has been seen in dietary factors), ${ }^{44}$ or age (seen in self-reported drug and alcohol use). ${ }^{45}$

We know from previous studies that ageing is likely to be a major factor contributing to the reduced prevalence of risky driving, ${ }^{27}{ }^{46-48}$ but it is difficult to differentiate the strength of the effect of age on the declining risk in comparison to other factors. Therefore, we have looked in detail at factors associated with a change from non-risky to risky driving.

We suggest two possible reasons for the reduction in risky driving behaviour that occurred in those deployed after 2007; a road safety campaign and/or changes in driving practices on deployment. Owing to the observational nature of this study, it is not possible to elucidate which of these factors accounted for this. In order to study the effects of the road safety campaign in depth, a more robust evaluation methodology would need to be adopted such as a cluster randomised controlled trial. In addition, to the possible explanations outlined, we have not looked at other factors (eg, mental health symptoms) that may explain some of the observed changes in driving behaviours over time.

\section{CONCLUSIONS}

Among a cohort of UK military personnel, the prevalence of risky driving reduced from $18 \%$ to $14 \%$, over an average time period of 3.3 years. Younger age and a history of alcohol misuse both predicted becoming a risky driver between the two surveys. There is some evidence that the military's road safety campaign which started in 2007 may have reduced the risk of becoming a risky driver. However, changes in driving practices during deployments after 2007 may also be responsible for these changes in risky driving behaviours.

Contributors RJSS wrote the introduction and discussion and contributed to the design and analysis of the study. HJF wrote the methods and results and contributed to the design and analysis of the study. SCW, NG, NJ, MF and KH contributed to the design of the study and commented throughout. NTF contributed to the design and analysis of the study.
Funding UK Ministry of Defence and Biomedical Research Centre.

Competing interests (1) NJ and MF are members of British Army, and they are paid by the UK Ministry of Defence (MoD). (2) SCW is Honorary Civilian Consultant Advisor in Psychiatry to the British Army and a Trustee of Combat Stress. (3) HJF, NG and NTF are funded by the MoD. (4) KH is a civilian member of the MoD.

Ethics approval MoD's research ethics committee (MODREC) and King's College Hospital local research ethics committee.

Provenance and peer review Not commissioned; externally peer reviewed.

Data sharing statement No additional data are available.

Open Access This is an Open Access article distributed in accordance with the Creative Commons Attribution Non Commercial (CC BY-NC 4.0) license, which permits others to distribute, remix, adapt, build upon this work noncommercially, and license their derivative works on different terms, provided the original work is properly cited and the use is non-commercial. See: http:// creativecommons.org/licenses/by-nc/4.0/

\section{REFERENCES}

1. National Highway Traffic Safety Administration (NHTSA), Traffic safety facts 2003. DOT publication number HS 809767 Washington DC: Department of Transportation, 2003.

2. Office for National Statistics. Cause of death registrations. 2006. www.statistics.gov.uk/downloads/theme_population/ Table 2 Death Registrations Cause.xls.

3. Defence Analytical Services Agency. UK Defence Statistics 2010, Chapter 3 Health. http://www.dasa.mod.uk/modintranet/UKDS/ UKDS2010/c3/deaths intro.php

4. DASA Defence Analytical Services Agency, Deaths in the UK Regular Armed Forces. 2006. http://www.dasa.mod.uk/applications/ newWeb/www/index.php?page $=48 \&$ thiscontent $=300 \&$ pubType $=$ 1 \&date $=2007-03-30 \&$ dis Text $=2006 \&$ from $=$ historic \& topDate $=2008$ 03-31\&PublishTime=00:00:01

5. Fear NT, Iversen AC, Chatterjee A, et al. Risky driving among regular armed forces personnel from the United Kingdom. Am J Prev Med 2008;35:230-6.

6. Bell NS, Amoroso PJ, Yore MM, et al. Self-reported risk-taking behaviors and hospitalization for motor vehicle injury among active duty army personnel. Am J Prev Med 2000;18:85-95.

7. Krull AR, Jones $B H$, Dellinger AM, et al. Motor vehicle fatalities among men in the US. Army from 1980 to 1997. Mil Med 2004;169:926-31.

8. Tavris DR, Kuhn EM, Layde PM. Age and gender patterns in motor vehicle crash injuries: importance of type of crash and occupant role. Accid Anal Prev 2001;33:167-72.

9. Armed Forces Health Surveillance Center. Update: motor vehiclerelated deaths, active and reserve components, US Armed Forces, 1999-2012. MSMR 2013;20:10-14.

10. Lincoln AE, Hooper TI, Kang HK, et al. Motor vehicle fatalities among Gulf War era veterans: characteristics, mechanisms, and circumstances. Traffic Inj Prev 2006;7:31-7.

11. Kang HK, Bullman TA. Mortality among US veterans of the Persian Gulf War. N Engl J Med 1996;335:1498-504.

12. Macfarlane GJ, Thomas E, Cherry N. Mortality among UK Gulf War veterans. Lancet 2000;356:17-21.

13. DASA Defence Analytical Services Agency, Statistical Notice. UK Gulf veterans mortality data. 2007. http://www.dasa.mod.uk/natstats/ gulf/intro.html

14. Kang HK, Bullman TA. Mortality among US veterans of the Persian Gulf War: 7-year follow-up. Am J Epidemiol 2001;154:399-405.

15. Macfarlane GJ, Hotopf M, Maconochie N, et al. Long-term mortality amongst Gulf War veterans: is there a relationship with experiences during deployment and subsequent morbidity? Int J Epidemiol 2005;34:1403-8.

16. Kang HK, Bullman TA, Macfarlane GJ, et al. Mortality among US and UK veterans of the Persian Gulf War: a review. Occup Environ Med 2002;59:794-9.

17. Amick MM, Kraft M, McGlinchey R. Driving simulator performance of Veterans from the Iraq and Afghanistan wars. J Rehabil Res Dev 2013;50:463-70.

18. Phillips RO, Ulleberg $P$, Vaa T. Meta-analysis of the effect of road safety campaigns on accidents. Accid Anal Prev 2011;43: 1204-18.

19. IVCA, Grim Reaper Video. 2008. http://www.youtube.com/watch? $\mathrm{v}=\mathrm{HKqo}$ V3DnRo 
20. Fear NT, Jones M, Murphy D, et al. What are the consequences of deployment to Iraq and Afghanistan on the mental health of the UK armed forces? A cohort study. Lancet 2010;375:1783-97.

21. Hotopf M, Hull L, Fear NT, et al. The health of UK military personnel who deployed to the 2003 Iraq war: a cohort study. Lancet 2006;367:1731-41.

22. MacManus D, Dean K, Iversen AC, et al. Impact of pre-enlistment antisocial behaviour on behavioural outcomes among UK military personnel. Soc Psychiatry Psychiatr Epidemiol 2012;47:1353-8.

23. Iversen AC, Fear NT, Simonoff E, et al. Influence of childhood adversity on health among male UK military personnel. $\mathrm{Br} J$ Psychiatry 2007;191:506-11.

24. Babor TF, Higgins-Biddle JC, Saunders JB, et al. AUDIT. The alcohol use disorders identification test. Geneva: World Health Organisation: 2001.

25. Browne T, Hull L, Horn O, et al. Explanations for the increase in mental health problems in UK reserve forces who have served in Iraq. Br J Psychiatry 2007;190:484-9.

26. Begg DJ, Langley JD. Road traffic practices among a cohort of young adults in New Zealand. N Z Med J 1999;112:9-12.

27. Jonah B. Age differences in risky driving. Health Educ Res 1990;5:139-49.

28. Hoggatt KJ, Prescott MR, Goldmann E, et al. The prevalence and correlates of risky driving behavior among National Guard soldiers. Traffic Inj Prev 2015;16:17-23.

29. Selzer ML, Vinokur A. Role of life events in accident causation. Ment Health Soc 1975;2:36-54.

30. Lagarde E, Chastang JF, Gueguen A, et al. Emotional stress and traffic accidents - the impact of separation and divorce. Epidemiology 2004;15:762-6.

31. Fertig JB, Allen JP. Health behavior correlates of hazardous drinking by army personnel. Mil Med 1996;161:352-5.

32. Stout RW, Parkinson MD, Wolfe WH. Alcohol-related mortality in the U.S. Air Force, 1990. Am J Prev Med 1993;9:220-3.

33. Williams JO, Bell NS, Amoroso PJ. Drinking and other risk taking behaviors of enlisted male soldiers in the US Army. Work 2002;18:141-50.

34. Spain DA, Boaz PW, Davidson DJ, et al. Risk-taking behaviors among adolescent trauma patients. J Trauma 1997;43:423-6.

35. Johnson V, White HR. An investigation of factors related to intoxicated driving behaviors among youth. J Stud Alcohol 1989;50:320-30.
36. Hingson RW, Howland J, Levenson S. Effects of legislative reform to reduce drunken driving and alcohol-related traffic fatalities. Public Health Rep 1988;103:659-87.

37. Burdett $\mathrm{H}$, Jones N, Fear NT, et al. Early psychosocial intervention following operational deployment: analysis of a free text questionnaire response. Mil Med 2011;176: $620-5$

38. Woodall KA, Jacobson IG, Crum-Cianflone NF. Deployment experiences and motor vehicle crashes among US service members. Am J Prev Med 2014;46:350-8.

39. Walter Reed Army Institute of Research. Battlemind Training II. Continuing the transition home. http://www.networkofcare.org/library/ Post-Deployment\%20Battlemind\%20Training\%20for\%20Soldiers2. pdf

40. Kuhn E, Drescher K, Ruzek J, et al. Aggressive and unsafe driving in male veterans receiving residential treatment for PTSD. J Trauma Stress 2010;23:399-402.

41. MOD (Defence Statistics Health), Deaths in the UK Regular Armed Forces: by year of occurrence and cause, numbers, 2000-2009 on the Gov.uk website. https://www.gov.uk/government/collections/ukarmed-forces-land-transport-accidents-index

42. Lindeman M, Verkasalo M. Personality, situation, and positivenegative asymmetry in socially desirable responding. Eur J Pers 1995:9:125-34.

43. Lajunen T, Summala H. Can we trust self-reports of driving? Effects of impression management on driver behaviour questionnaire responses. Transportation Res Part F 2003;6:97-107.

44. Hebert JR, Ma YS, Clemow L, et al. Gender differences in social desirability and social approval bias in dietary self-report. $A m \mathrm{~J}$ Epidemiol 1997;146:1046-55.

45. Welte JW, Russell M. Influence of socially desirable responding in a study of stress and substance-abuse. Alcohol Clin Exp Res 1993;17:758-61.

46. Jessor R, Turbin MS, Costa FM. Predicting developmental change in risky driving: the transition to young adulthood. Appl Dev Sci 1997;1:4-16.

47. Zuckerman M. Sensation seeking: beyond the optimal level of arousal. Hillsdale, NJ: Erlbaum, 1979.

48. Lawton R, Parker D, Stradling SG, et al. Predicting road traffic accidents: the role of social deviance and violations. Br J Psychol 1997;88:249-62. 